\title{
Revisited: Monopoly and Long-Run Capital Accumulation in Two-Sector Overlapping Generation Model
}

\author{
Ronald Ravinesh Kumar ${ }^{1}$ (D) and Peter J. Stauvermann ${ }^{2, *(D)}$ \\ 1 School of Accounting, Finance and Economics, Laucala Campus, The University of the South Pacific, \\ Suva 40302, Fiji; ronald.kumar@usp.ac.fj \\ 2 Department of Global Business and Economics, Changwon National University, Changwon 51140, Korea \\ * Correspondence: pjsta@changwon.ac.kr
}

Citation: Kumar, Ronald Ravinesh, and Peter J. Stauvermann. 2021

Revisited: Monopoly and Long-Run Capital Accumulation in Two-Sector Overlapping Generation Model. Journal of Risk and Financial Management 14: 304. https:// doi.org/10.3390/jrfm14070304

Academic Editor: Michael McAleer

Received: 17 June 2021

Accepted: 28 June 2021

Published: 3 July 2021

Publisher's Note: MDPI stays neutral with regard to jurisdictional claims in published maps and institutional affiliations.

Copyright: (c) 2021 by the authors. Licensee MDPI, Basel, Switzerland. This article is an open access article distributed under the terms and conditions of the Creative Commons Attribution (CC BY) license (https:// creativecommons.org/licenses/by/ $4.0 /)$
Abstract: In this paper, we investigate if an increasing competition in an oligopolistic market will enhance the real incomes and consumer surplus in the long run. For this purpose, we apply a twosector overlapping generation model in which members of the young generation own the oligopolistic firms. We show that increasing competition in the oligopolistic market leads to ambiguous outcomes regarding the real income and consumer surplus in the long run. However, we show that the distribution of income will become fairer if the competition increases, but it is possible that the price for a fairer distribution is a lower income for all members of the economy.

Keywords: oligopolistic competition; two-sector overlapping generations; consumer surplus; real income

\section{Introduction}

The aim of this paper is to investigate the long-run consequences of imperfect competition in a neoclassical two-sector model of economic growth. Particularly, we are interested in two questions. First, we want to know if the existence of an imperfectly competitive market leads to inefficiencies measured in terms of consumer surplus and real aggregate income in the long run. Second, we want to know if the existence of an imperfectly competitive market leads to a more unequal distribution of income. Mostly, it presumed in the literature that imperfect competitive markets lead to inefficiency in terms of consumer surplus, and to a more unequal distribution of income. However, there are only few models which come to these conclusions in a dynamic setting.

As a reference, we use the model of Laitner (1982), which has recently received some attention (c.f. Shy and Stenbacka 2019a, 2019b). Laitner (1982) uses a Diamond's (1965) overlapping generations (OLG) model with two sectors, where one sector is perfectly competitive and the other has the structure of a Cournot oligopoly. The aim of Laitner was to investigate the static and dynamic welfare losses created by the oligopolistic sector. In fact, he detected static and dynamic welfare losses caused by the oligopolistic market. The static welfare losses result from the distortion of the relative prices and the dynamic welfare losses occur by crowding-out the savings of the young generation devoted to investment in capital through the purchase of oligopolistic firms. In this study, we show that the outcomes of Laitner (1982) no longer hold if members of the young generation, instead of the old generation, are the owners of the oligopolistic firms. The results derived in this paper are close to the one-good OLG model of Kumar and Stauvermann $(2020,2021)$, who have shown that more competition does not necessarily increase the welfare, and under certain conditions, it can lead to less growth and less welfare.

The outcomes from the analysis presented in this study show that imperfect competition does not reduce the real income and consumer surplus in general and that the outcomes of imperfect competition depend on how the rents earned in the imperfectly competitive markets are utilized. 
The rest of the paper is organized as follows. In Section 2, we provide an overview of the consequences of imperfect competitive markets. In Section 3, we introduce the model, and in Section 4, we analyze the effects due to a decline in the degree of monopoly. In Section 5, we conclude the paper.

\section{Literature Review}

Most students of economics and business learn in their first year of study that oligopolies and monopolies are bad (e.g., Mankiw 2020), because they induce inefficiencies and welfare losses, where the latter is usually shown with the concept of consumer surplus in a static partial equilibrium model (Marshall 1890). Although Marshall's approach had some weaknesses regarding the assumed utility function and consideration of income (Dooley 1983), it is widely argued that monopolies and oligopolies should be avoided because their existence lead to inefficiencies and welfare losses.

A second problem which is associated with monopolies and oligopolies results from the fact that their existence leads to a more unequal distribution of income and wealth. For example, Barkai and Benzell (2018) and Barkai (2020) explain the decline of the labor income share in the last 40 years with respect to the market power of firms (c.f. Elsby et al. 2013; Karabarbounis and Neiman 2014, 2018). Autor et al. $(2017,2020)$ explain this decline with the monopoly power caused by network economies, which we observe in digital markets. Examples of these so-called superstar firms are Google, Uber, Facebook, AirBnB, Twitter, Apple, or Microsoft.

Laitner (1982) was the first to introduce imperfect competition in a two-sector OLG model of economic growth, where one sector is assumed to be perfectly competitive and the other is like a Cournot oligopoly. The number of firms is exogenously given, and part of the savings are used to purchase the oligopolistic firms from the old generation. Particularly, these purchases of firms crowd out the investment in physical capital with the consequence that the more concentrated the oligopoly, the lower he steady-state capital stock is. Additionally, since the goods produced in the two sectors are substitutable in consumption, the market power of the oligopolist creates distortion of the allocation of factors in the whole economy. Laitner (1982) shows that the welfare in terms of real income and consumer surplus will be increased if the number of firms in the oligopolistic sector increases. Additionally, the steady-state capital stock will increase. Eaton (1989) has extended Laitner's argument that monopoly rents have portfolio implications, by considering an open economy. He shows that capitalized assets based on governmentguaranteed monopoly rents increase international indebtedness of the respective country. In the same line, Mitchell (1995) analyzes the effect of monopolized quota rents and comes to similar conclusions as Eaton (1989).

Kumar and Stauvermann $(2020,2021)$ have developed two different one-good OLG models with Cournot competition. The difference between both approaches is that Kumar and Stauvermann (2020) assume an AK production function, so that the resulting model is an endogenous growth model, whereas Kumar and Stauvermann (2021) use a neoclassical standard production function so that the model follows a Diamond's (1965) OLG model with Cournot competition. However, the outcomes of both models are relatively similar; in the former model, more competition may lead to varying rates of economic growth, which depends on the savings rate and the production elasticity of capital. In the latter model, the steady-state capital stock may vary depending on the savings rate and the production elasticity of capital. Thus, the main conclusion of both models is that imperfect competition may lead to an equilibrium which guarantees a higher level of growth and welfare. In other words, it can be argued that imperfect competition is no worse than perfectly competitive markets. Similarly, the model of this paper confirms the results of Kumar and Stauvermann $(2020,2021)$, if the members of the young generation are the owners of the oligopolistic firms.

In another study, Belan et al. (2005) consider a developing country and assume only two classes, a capitalist and a worker, and that only the capitalists accumulate capital. 
In this model, where capitalists exploit workers via non-competitive behavior, capital accumulation, and growth are positively affected as long as the capitalists do not face borrowing constraints on the international capital market. Under these circumstances, the employment and wages are positively affected. If the capitalists face borrowing constraints, the results are reversed.

A different approach was developed by Belan et al. (2007), who assumed oligopolistic pension funds in an OLG model with bequests, so that the capital market is no longer competitive. They show that the capital stock can be higher with pension funds than without them, given that the bequests are operative and that the pension-fund contributions are subsidized. Consequently, the welfare can be increased by non-competitively behaving pension funds under the given circumstances. If bequests are constrained, the positive effect of pension funds is no longer guaranteed.

Chou and Shy (1991) developed an OLG model in which the only source of saving is the construction of new firms, which yield monopoly profits. The model includes the approach of Dixit and Stiglitz (1977) and Ethier (1982) to establish monopolistic competition in the intermediate goods sector. They show that economic growth can be endogenous and unbounded.

Tse (2000) considered imperfect markets where labor skills are sector-specific, and that there are barriers to entry in the labor market, so that the labor market in one sector (industry) is a monopsony. Therefore, the workers in this sector are paid less than their marginal product of labor. Using calibrations, the study shows that, in a two-sector model, the welfare losses generated by the monopsony are significant in the long run, due to reduced human and physical capital accumulation. Consequently, the author argues that, to enhance growth and welfare, the monopsony power in the labor market must be reduced.

Parente and Prescott (1999) developed a model to show that non-competitive behavior in markets can cause significant welfare losses. They argue that the aggregate output can be increased by factor of three without any increase in input, if all markets become perfectly competitive. They argue that, in imperfect competition, some individuals (factor suppliers) have monopoly rights that are tied to the production processes. Thus, in their model, the monopolistic factor suppliers impede economic growth by preventing the use of superior technologies, and therefore they propose that governments should abolish the protection of monopoly rights to enhance growth and welfare.

Busato and Chiarini's (2005) study differs from the others in that they require that theoretical models should contain existing market imperfections for analysis and derivation of policy recommendations. Their argument is that models containing market imperfections may deliver better results regarding stylized facts than models based on the assumption of perfectly competitive markets, because the real world is full of market imperfections and other market failures. Particularly, they argue that European labor markets are characterized by monopoly power executed by trade unions. By considering this argument in a model and assuming different degrees of market power, they explain why the production is relatively capital-intensive in Europe, and they derive proposals regarding plausible reforms of institutional agreements on labor unions to enhance employment and growth.

Based on these papers, which have considered oligopolistic competition in a dynamic or OLG setting, we can state that a majority of them confirm that oligopolies not only distort the factor allocation but can also lead to the reduction of capital accumulation. However, the latter effect only exists if the members of old generation own the oligopolistic firms.

\section{The Model}

\subsection{The Households}

As noted above, we are considering a two-period OLG model of the Diamond (1965) type, where we assume that all individuals are identical and that the population is constant. In the first period of life, the representative individual has an inelastic labor supply and saves part of her income. Moreover, some members of the young generation are bequeathed 
with firms from their (retiring age) parents. The firm owners' income comprises a wage rate and the profit made by the firm. The number of firms is limited to $n$. The rest of the young generation earn only a wage income. In the second period of life, the individuals live from their savings and the respective interest payments.

Further, we assume that the representative individual has an index function to produce the quantity of real consumption good, $x_{t}$, from the two goods produced in this economy. The index function is a Cobb-Douglas function:

$$
x_{t}=\left(x_{t}^{C}\right)^{\beta}\left(x_{t}^{O}\right)^{1-\beta}
$$

with $0<\beta<1$ and where $x_{t}^{C}$ is the quantity of goods produced in the competitive sector of the economy and $x_{t}^{O}$ is the quantity of goods produced by the oligopolistic sector of the economy. Both goods are necessary to produce the real consumption goods, $x_{t}$. The price of the good produced in the competitive sector is the numeraire in this economy and the price of the good produced in the oligopolistic sector is $p^{*}$ in both periods, where $p^{*}$ is in fact constant over time, as we show below. First, we calculate how much of $x_{t}$ can be produced by one unit of income or with a budget $b$, where $b=1$. For this purpose, the respective budget constraint becomes the following:

$$
x_{t}^{C}+p^{*} x_{t}^{O}=1 .
$$

Maximizing (1) with respect to (2) delivers the first-order condition:

$$
p^{*}=\left(\frac{1-\beta}{\beta}\right) \frac{x_{t}^{C}}{x_{t}^{O}} .
$$

Because of the fact that the price, $p^{*}$, is time invariant, the optimal ratio between goods from the competitive sector and the oligopolistic sector is constant. Using (3), we can calculate the quantity of $x_{t}$, given that the budget is one unit of income.

$$
\left.x_{t}\right|_{b=1}=\beta^{\beta}\left(\frac{1-\beta}{p^{*}}\right)^{1-\beta} .
$$

Equation (4) explains how much consumption goods can be purchased with one unit of income. The inverse of function (4) delivers the cost per unit $\left(z_{t}\right)$ of the real consumption good:

$$
z_{t}=z=\left(\frac{1}{1-\beta}\right)\left(\frac{\beta}{1-\beta}\right)^{-\beta}\left(p^{*}\right)^{1-\beta} .
$$

The utility function is a CIES function depending on the consumption of $x_{t}$ and $x_{t+1}$ :

$$
U\left(x_{t}, x_{t+1}\right)=\frac{\left(x_{t}\right)^{\sigma}}{\sigma}+q \frac{\left(x_{t+1}\right)^{\sigma}}{\sigma},
$$

where $0<q \leq 1$ and $\sigma<1$. The latter condition ensures a positive interest elasticity of savings, and $q$ represents the subjective discount factor. In the case that $\sigma=0$, the utility function becomes a log-linear consumption function:

$$
U\left(x_{t}, x_{t+1}\right)=\ln x_{t}+q \ln x_{t+1} .
$$

The intertemporal budget constraint is given by the following:

$$
z x_{t}+\frac{z x_{t+1}}{R_{t+1}}=y_{t},
$$

where $y_{t}$ is the income in the first period of life. Maximizing the utility with respect to the budget constraint (8), we get the following savings function: 


$$
s_{t}=\chi\left(R_{t+1}\right) y_{t},
$$

where

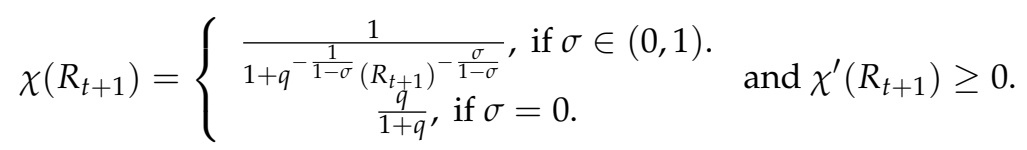

This means the savings rate is identical for all individuals.

\subsection{The Firms}

As noted above, we consider two sectors, where both sectors use the same technology:

$$
Q_{t}^{i}=A\left(K_{t}^{i}\right)^{\alpha}\left(L_{t}^{i}\right)^{1-\alpha}, \text { for } i=C, O \text { and } \alpha \in(0,1),
$$

where the superscripts $C$ and $O$ indicate the competitive and the oligopolistic sector, respectively. We assume that the capital is fully depreciated after one period. Further, we define the following:

$$
K_{t}=K_{t}^{O}+K_{t}^{C} .
$$

and

$$
L=L_{t}^{O}+L_{t}^{C} .
$$

The firms in both sectors are profit maximizers and competing for the production factors. Regarding the oligopolistic sector, we assume a Cournot competition where $n$ is the fixed number of oligopolists in the market. Therefore, the first-order conditions for a profit maximization are given by the following:

$$
\begin{gathered}
w_{t}=p_{t}\left(\frac{n-1}{n}\right)(1-\alpha) A\left(K_{t}^{O}\right)^{\alpha}\left(L_{t}^{O}\right)^{-\alpha}=p_{t}\left(\frac{n-1}{n}\right)(1-\alpha) \frac{Q_{t}^{O}}{L_{t}^{O}} \\
R_{t}=p_{t}\left(\frac{n-1}{n}\right) \alpha A\left(K_{t}^{O}\right)^{\alpha-1}\left(L_{t}^{O}\right)^{1-\alpha}=p_{t}\left(\frac{n-1}{n}\right) \alpha \frac{Q_{t}^{O}}{K_{t}^{O}}
\end{gathered}
$$

where $p_{t}$ is the price per unit of a good produced in the oligopolistic sector. The aggregate profits in this sector account to the following:

$$
\Pi_{t}^{O}=\frac{p_{t} Q_{t}^{O}}{n} .
$$

An oligopolist sets a price, so that we get the following:

$$
p_{t}\left(1-\frac{1}{n}\right)=M C
$$

Because of the linear homogeneity of the production function, the marginal costs are equal to the costs of one unit of output. Therefore, the price of the product produced by the oligopolistic sector is obtained as follows:

$$
p_{t}=p^{*}=\frac{n}{n-1} .
$$

Since the good produced in the competitive sector is the numeraire good, the price of a unit of this good is one. The conditions for profit maximization in the competitive sector are given by the following:

$$
w_{t}=(1-\alpha) A\left(K_{t}^{C}\right)^{\alpha}\left(L_{t}^{C}\right)^{-\alpha}=(1-\alpha) \frac{Q_{t}^{C}}{L_{t}^{C}},
$$




$$
R_{t}=\alpha A\left(K_{t}^{C}\right)^{\alpha-1}\left(L_{t}^{C}\right)^{1-\alpha}=\alpha \frac{Q_{t}^{C}}{K_{t}^{C}}
$$

\subsection{The Equilibrium}

From (13), (14), (16), (18) and (19), we get the following:

$$
\frac{K_{t}^{C}}{L_{t}^{C}}=\frac{K_{t}^{O}}{L_{t}^{O}}=\frac{K_{t}}{L} .
$$

This means the capital intensity is equal in both sectors of the economy. Define $\frac{1}{1+\theta_{t}}$ as share of resources used in the competitive sector and $\left(1-\frac{1}{1+\theta_{t}}\right)=\frac{\theta_{t}}{1+\theta_{t}}$ as share of resources used in the oligopolistic sector. Then we can write the following:

$$
\begin{aligned}
K_{t}^{C} & =\frac{1}{1+\theta_{t}} K_{t}, \\
L_{t}^{C} & =\frac{1}{1+\theta_{t}} L, \\
K_{t}^{O} & =\frac{\theta_{t}}{1+\theta_{t}} K_{t}, \\
L_{t}^{O} & =\frac{\theta_{t}}{1+\theta_{t}} L .
\end{aligned}
$$

Further, we define $Z_{t}=A K_{t}^{\alpha} L^{1-\alpha}$. Using this definition and (21)-(24), we can write the following:

$$
\begin{aligned}
& Q_{t}^{C}=\frac{1}{1+\theta_{t}} Z_{t}, \\
& Q_{t}^{O}=\frac{\theta_{t}}{1+\theta_{t}} Z_{t} .
\end{aligned}
$$

Accordingly, the wage rate, interest factor, and profits can be written as follows:

$$
\begin{gathered}
w_{t}=(1-\alpha) A\left(K_{t}\right)^{\alpha}\left(L_{t}\right)^{-\alpha}=(1-\alpha) A\left(k_{t}\right)^{1-\alpha}, \\
R_{t}=\alpha A\left(K_{t}\right)^{\alpha-1}\left(L_{t}\right)^{1-\alpha}=\alpha A\left(k_{t}\right)^{-\alpha}, \\
\Pi_{t}^{O}=\left(\frac{1}{n-1}\right)\left(\frac{\theta_{t}}{1+\theta_{t}}\right) A K_{t}^{\alpha} L^{1-\alpha} .
\end{gathered}
$$

From (25) and (26), we can derive the following:

$$
\theta_{t}=\frac{Q_{t}^{O}}{Q_{t}^{C}}
$$

Therefore, $\theta_{t}$ represents the ratio between the quantity of goods produced in the oligopolistic sector and the quantity produced in the competitive sector.

Further, we assume that only goods produced in the competitive sector can be consumed and used as investment good. The goods produced in the oligopolistic sector can only be used for consumption purposes and not for investment. We define $\psi$ as the share of the competitive sector's production which is consumed. Thus, the aggregate consumption of goods produced in the competitive sector, $C_{t}^{C}$, can be written as follows:

$$
C_{t}^{C}=\psi_{t} Q_{t}^{C},
$$


Accordingly, based on the assumption regarding the consumption of the good produced in the oligopolistic sector, the aggregate consumption of goods produced in the oligopolistic sector, $C_{t}^{O}$, is as follows:

$$
C_{t}^{O}=Q_{t}^{O}
$$

Using (3) and (17) together with (31) and (32), we can state the following:

$$
\frac{x_{t}^{C}}{x_{t}^{O}}=\frac{C_{t}^{C}}{C_{t}^{O}}=\frac{\psi_{t} Q_{t}^{C}}{Q_{t}^{O}}=\left(\frac{\beta}{1-\beta}\right)\left(\frac{n}{n-1}\right) .
$$

We can reformulate Equation (33) with the result for $\theta_{t}$ from Equation (30):

$$
\psi_{t}=p^{*}\left(\frac{\beta}{1-\beta}\right) \frac{Q_{t}^{O}}{Q_{t}^{C}}=\left(\frac{n}{n-1}\right)\left(\frac{\beta}{1-\beta}\right) \theta_{t} .
$$

Because of the fact that $\psi_{t}$ represents the share of the goods of the competitive sector which are consumed, the share $1-\psi_{t}$ represents the share of the goods of the competitive sector which are used as capital in period $t+1$. Hence, the investments, $I_{t}$, equal the capital stock in the following period, $t+1$. The investments can be written as follows:

$$
I_{t}=K_{t+1}=\left(1-\psi_{t}\right)\left(\frac{1}{1+\theta_{t}}\right) A K_{t}^{\alpha} L^{1-\alpha} .
$$

Inserting (34) in (35) delivers the following:

$$
K_{t+1}=\left(1-\left(\frac{n}{n-1}\right)\left(\frac{\beta}{1-\beta}\right) \theta_{t}\right)\left(\frac{1}{1+\theta_{t}}\right) A\left(K_{t}\right)^{\alpha} L^{1-\alpha} .
$$

Now solving for $\theta_{t}$ gives the solution as follows:

$$
\theta_{t}=\frac{(1-\beta)(n-1)\left(A\left(K_{t}\right)^{\alpha} L^{1-\alpha}-K_{t+1}\right)}{\beta n A\left(K_{t}\right)^{\alpha} L^{1-\alpha}+K_{t+1}(1-\beta)(n-1)} .
$$

The total savings, $S_{t}$, are given by the savings rate, $\chi\left(R_{t+1}\right)$, which is identical for all members of the young generation times the sum of wage incomes and aggregated profit incomes, expressed as follows:

$$
S_{t}=\chi\left(R_{t+1}\right)\left(w_{t} L+\frac{p_{t} Q_{t}^{O}}{n}\right) .
$$

Now we insert (26)-(28) and (37) in (38) to get the capital market clearing condition $S_{t}=K_{t+1}$.

$$
K_{t+1}=\chi\left(\alpha A\left(K_{t+1}\right)^{\alpha-1} L^{1-\alpha}\right)\left[(1-\alpha) A\left(K_{t}\right)^{\alpha} L^{1-\alpha}+\frac{(1-\beta)}{\beta+n-1}\left(A\left(K_{t}\right)^{\alpha} L^{1-\alpha}-K_{t+1}\right)\right] .
$$

In per capita terms, we get the following:

$$
\chi\left(\alpha A\left(k_{t+1}\right)^{\alpha-1}\right)\left[(1-\alpha) A\left(k_{t}\right)^{\alpha}+\frac{(1-\beta)}{\beta+n-1}\left(A\left(k_{t}\right)^{\alpha}-k_{t+1}\right)\right]-k_{t+1}=0 .
$$

Although the original Laitner (1982) model differs in that the profits are received by the old generation, the proof for the existence of a unique equilibrium can be analogous in this model. Regarding the local stability of the model, which was not considered by Laitner, we use the implicit function theorem, and this delivers the following: 


$$
\frac{d k_{t+1}}{d k_{t}}=-\frac{\chi\left(\alpha A\left(k_{t+1}\right)^{\alpha-1}\right) \alpha A\left(k_{t}\right)^{\alpha-1}\left((1-\alpha)+\frac{(1-\beta)}{\beta+n-1}\right)}{\chi^{\prime}\left(\alpha A\left(k_{t+1}\right)^{\alpha-1}\right) \alpha(\alpha-1) A\left(k_{t+1}\right)^{\alpha-2}\left[(1-\alpha) A\left(k_{t}\right)^{\alpha}+\frac{(1-\beta)}{\beta+n-1}\left(A\left(k_{t}\right)^{\alpha}-k_{t+1}\right)\right]-\chi\left(\alpha A\left(k_{t+1}\right)^{\alpha-1}\right) \frac{(1-\beta)}{\beta+n-1}-1}
$$
to hold:

Therefore, in the steady-state equilibrium with $k_{t+1}=k_{t}=k^{*}>0$, the following has

$$
\frac{d k_{t+1}}{d k_{t}}=-\frac{\chi\left(\alpha A\left(k^{*}\right)^{\alpha-1}\right) \alpha A\left(k^{*}\right)^{\alpha-1}\left((1-\alpha)+\frac{(1-\beta)}{\beta+n-1}\right)}{\chi^{\prime}\left(\alpha A\left(k^{*}\right)^{\alpha-1}\right) \alpha(\alpha-1) A\left(k^{*}\right)^{\alpha-2}\left[(1-\alpha) A\left(k^{*}\right)^{\alpha}+\frac{(1-\beta)}{\beta+n-1}\left(A\left(k^{*}\right)^{\alpha}-k^{*}\right)\right]-\chi\left(\alpha A\left(k^{*}\right)^{\alpha-1}\right) \frac{(1-\beta)}{\beta+n-1}}<1 .
$$

This condition is fulfilled, if the interest elasticity of savings with respect to the interest factor is non-negative, $\frac{\chi^{\prime}(R)}{\chi(R)} R \geq 0$. Thus, the unique equilibrium in this model is locally stable. Without any loss of generality, we normalize the population to one, $L=1$. Thus, $K^{*}=k^{*}$.

The aggregate real consumption in each period is given by the following:

$$
C_{t}=\left(C_{t}^{O}\right)^{1-\beta}\left(C_{t}^{C}\right)^{\beta}
$$

and the real income, $Q_{t}$, in terms of Bergson (1973), is given by the following:

$$
Q_{t}=\left(Q_{t}^{O}\right)^{1-\beta}\left(Q_{t}^{C}\right)^{\beta}
$$

The quantity of $Q_{t}$ is, in the sense of Harberger (1954), the aggregate consumer surplus in this economy. We insert (25) and (26) in (44) to get the following:

$$
Q^{*}=\left(\frac{\theta^{*}}{1+\theta^{*}} Z^{*}\right)^{1-\beta}\left(\frac{1}{1+\theta^{*}} Z^{*}\right)^{\beta}=\frac{\left(\theta^{*}\right)^{1-\beta}}{1+\theta^{*}} Z^{*}=\frac{\left(\theta^{*}\right)^{1-\beta}}{1+\theta^{*}} A\left(k^{*}\right)^{\alpha} .
$$

Accordingly, we get the total real consumption as follows:

$$
C^{*}=\left(\frac{\theta^{*}}{1+\theta^{*}} Z^{*}\right)^{1-\beta}\left(\psi^{*} \frac{1}{1+\theta^{*}} Z^{*}\right)^{\beta}=\frac{\left(\psi^{*}\right)^{\beta}\left(\theta^{*}\right)^{1-\beta}}{1+\theta^{*}} Z^{*},
$$

By substituting the equilibrium value of $\psi^{*}$ from (34) and the definition of $Z$ in (46) and simplifying, we get the following:

$$
C^{*}=\left(\frac{n}{n-1}\right)\left(\frac{\beta}{1-\beta}\right) \frac{\theta^{*}}{1+\theta^{*}} A\left(k^{*}\right)^{\alpha} .
$$

\section{Comparative Statics}

\subsection{Efficiency of Factor Allocation}

The quantities $Q^{*}$ and $C^{*}$ are measuring the aggregate real income and the aggregated real consumption per period of the whole society. We consider these two variables to discuss the difference in the outcomes between our approach and the approach of Laitner (1982). Laitner (1982) focused on these variables and showed that the derivatives of $Q^{*}$ and $C^{*}$ with respect to the number of firms in the oligopolistic market are strictly positive. However, these outcomes do not hold necessarily if the firm owners are members of the young generation.

We are interested in changes of the steady-state equilibrium. Particularly, we want to know how the relevant variables will change, if the number of firms in the oligopolistic sector will increase. In other words, we are interested in the changes induced when the 
competition in the oligopolistic sector is becoming tougher. Therefore, the most important aspect is the change of the capital intensity, given by the following:

$$
\frac{d k^{*}}{d n}=\frac{\frac{(1-\beta)}{(\beta+n-1)^{2}}}{\chi^{\prime}\left(R^{*}\right) \alpha(\alpha-1) A\left(k^{*}\right)^{\alpha-2}\left[w^{*}+\frac{(1-\beta)}{\beta+n-1}\left(A\left(k^{*}\right)^{\alpha}-k^{*}\right)\right]+\chi\left(R^{*}\right) \alpha A\left(k^{*}\right)^{\alpha-1}\left[(1-\alpha)+\frac{(1-\beta)}{\beta+n-1}\left(1-\frac{1}{R^{*}}\right)\right]-1}<0 .
$$

The numerator of (49) is obviously positive, and the denominator is negative because of the stability condition (42). From this, we can derive the following proposition.

Proposition 1. In a two-sector model with an imperfect competitive market, an increase of an oligopolistic market's number of firms leads to a decline of the steady-state capital stock and capital intensity, given the local stability of the steady-state equilibrium.

This means that the steady-state capital intensity is declining if the number of firms is increasing. The reason for this outcome is that the effect that the income of the young generation, which consists of wage and profit incomes, will decline if the number of firms increases in the oligopolistic sector. Decisive for this result is that the profit share of the firms will decline, while the income shares of the capital owner and wage earners will increase, if the number of firms increases. Because of this consideration, the income share received by the young generation will also decline. Consequently, the steady-state capital stock will decline if the competition in the oligopolistic sector becomes tougher. This result is the opposite of the result derived by Laitner (1982). In his model, the old generation owns the firms, and if the profit share declines, the income share of the young working generation increases, and, additionally, they will invest less of their savings in firm shares and more in physical capital, even if the interest rate declines. As a consequence, a tougher competition in the oligopolistic sector increases the steady-state capital stock.

To get a deeper understanding, we consider the change of the ratio between the quantities produced in the oligopolistic and competitive sector. In the steady-state equilibrium, the ratio, $\theta^{*}$, can be written as follows:

$$
\theta^{*}=\frac{(1-\beta)(n-1)\left(R^{*}-\alpha\right)}{\alpha(1-\beta)(n-1)+R^{*} \beta n} .
$$

Differentiating (43) with respect to the number of firms delivers the following:

$$
\frac{\partial \theta^{*}}{\partial n}=\frac{(1-\beta)\left(R^{*}-\alpha\right) R^{*} \beta}{\left(\beta n R^{*}+\alpha(1-\beta)(n-1)\right)^{2}}+\frac{(1-\beta)(n-1) \alpha(\beta+n-1)}{\left(\beta n R^{*}+\alpha(1-\beta)(n-1)\right)^{2}}\left(\frac{d R^{*}}{d K}\right)\left(\frac{d k^{*}}{d n}\right)>0 .
$$

Proposition 2. If the number of firms in the oligopolistic sector increases, the production will shift from the competitive to the oligopolistic sector.

This result is as expected, because the price of the good produced in the oligopolistic sector decreases with an increasing number of firms. Therefore, the relative price of the good produced in the competitive sector is becoming more expensive, so that relatively less of these goods are demanded, while the relative demand for the goods in the oligopolistic sector increases.

However, this does not necessarily mean that the output of the oligopolistic sector will increase if the competition in this sector becomes tougher. To show what will happen with the steady-state outputs of both sectors, we differentiate Equations (25) and (26):

$$
\frac{d Q^{C *}}{d n}=\underbrace{-\frac{Z^{*}}{\left(1+\theta^{*}\right)^{2}} \frac{\partial \theta^{*}}{\partial n}}_{-}+\underbrace{\frac{1}{1+\theta^{*}} \frac{\partial Z}{\partial K} \frac{\partial K^{*}}{\partial n}}_{-}<0 .
$$




$$
\frac{d Q^{O *}}{d n}=\underbrace{\frac{Z^{*}}{\left(1+\theta^{*}\right)^{2}} \frac{\partial \theta^{*}}{\partial n}}_{+}+\underbrace{\frac{\theta^{*}}{1+\theta^{*}} \frac{\partial Z}{\partial K} \frac{\partial K^{*}}{\partial n}}_{-} \lesseqgtr 0 .
$$

As in Laitner (1982), the changes of the quantities of the competitive and oligopolistic sector can be split up into a static and a dynamic effect. The first summand in (51) and (52) represents the static effect, which is caused by the increasing competition in the oligopolistic sector and which indicates the change of the allocation of input factors. This results in a reallocation of input factors from the competitive to the oligopolistic sector, and thus leads to an increase of the output in the latter sector and to a decline of the output of the former sector. In other words, the reallocation of input factors takes place because the increasing competition reduces the distortions caused by the oligopolistic market structure. The increasing competition leads to a decline of the price of the goods produced in the oligopolistic sector, which increases the relative price of the goods produced in the competitive sector, so that the demand for goods in the oligopolistic sector will increase and the demand for goods produced in the competitive sector will decrease.

The second summand in (51) and (52) represents a dynamic effect, which is caused by the decline of the capital stock in the long run. This effect leads to a reduction of output in both sectors. While the overall effect regarding the quantity of goods produced in the competitive is uniquely negative, the overall effect on the quantity of goods produced in the oligopolistic sector is ambiguous. To illustrate this, we have calibrated the outcomes for the case of a log-linear utility function and a Cobb-Douglas production function (see Figures 1-3).

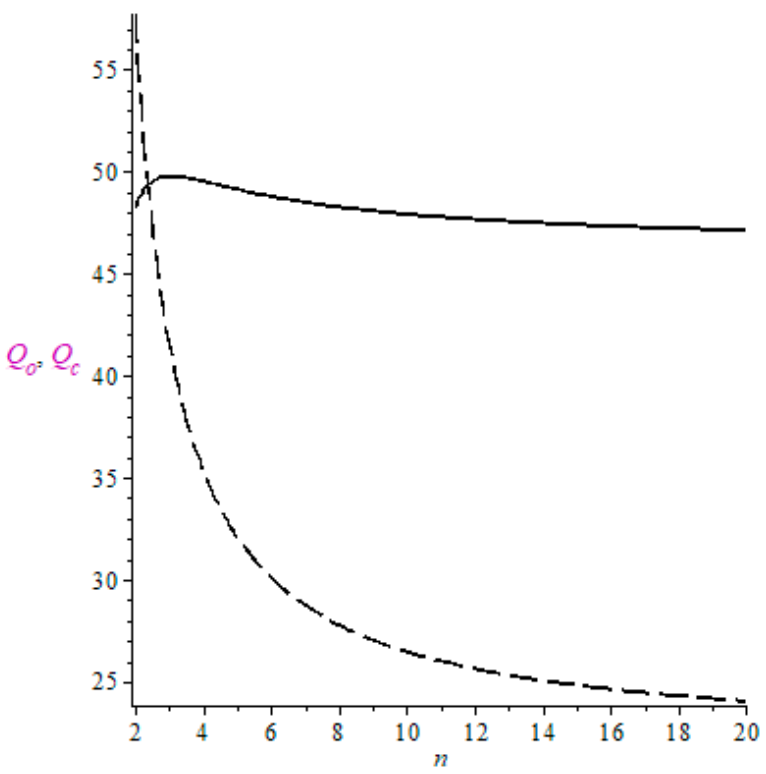

Figure 1. For the calibration, we used the following parameter values: $q=0.8, A=20, \beta=0.09$, and $\alpha=0.43$.

In all figures, the solid line represents the steady-state equilibrium output of the oligopolistic sector, while the dashed line represents the steady-state output of the competitive sector. To calibrate the three figures, we only changed the value of $\alpha$, which represents the production elasticity of capital. If the elasticity is sufficiently low, the output of the oligopolistic sector increases, as in Figure 2, if the elasticity is sufficiently high, the output always declines with an increasing number of competitors, as in Figure 3; and within certain range of the elasticity coefficients, the output increases with $n$ and then reaches a maximum, and thereafter the output declines. 


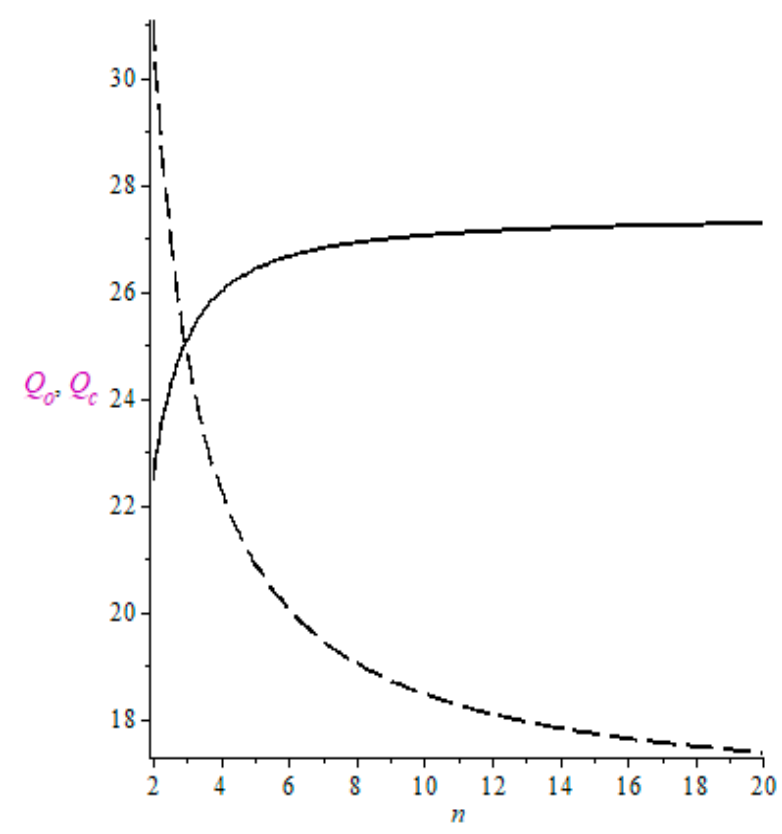

Figure 2. To calibrate Figure 2, we used the following parameter values: $q=0.8, A=20, \beta=0.09$, and $\alpha=0.3$.

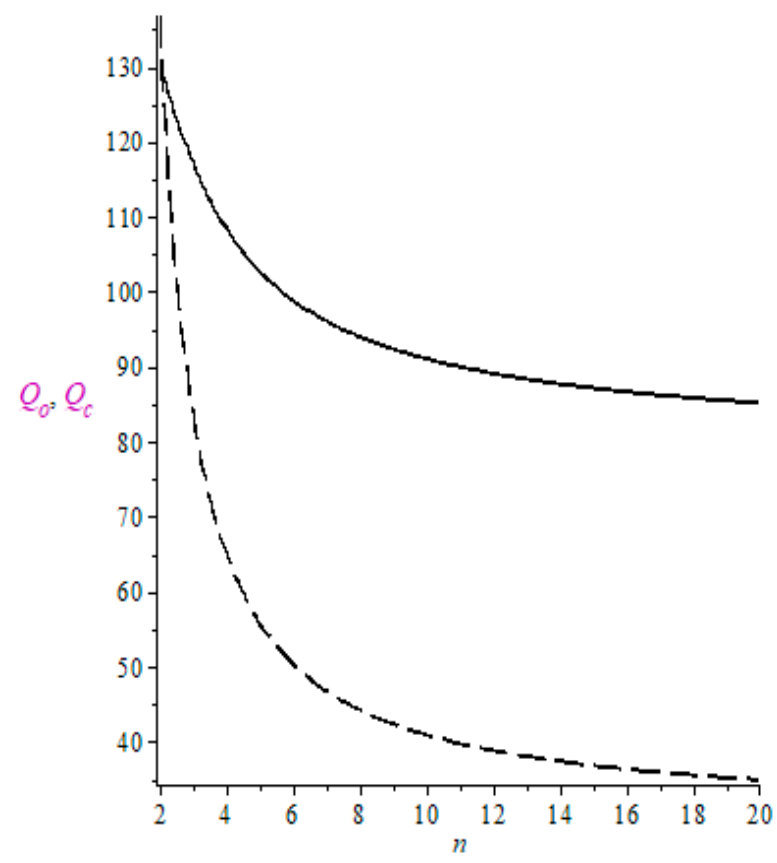

Figure 3. To calibrate Figure 3, we used the following parameter values: $q=0.8, A=20, \beta=0.09$, and $\alpha=0.55$.

Proposition 3. An increase of the number of firms in the competitive sector leads to a decline of the steady-state output of the competitive sector and to an ambiguous change of output produced in the oligopolistic sector.

As noted above, the real income is represented by the quantity of the compounded real consumption good, $Q$.

Proposition 4. If the competition in the oligopolistic sector becomes tougher, the reaction of the real income is ambiguous. 
Proof of Proposition 4. Differentiation of Equation (45) with respect to the number of firms leads to the following result:

$$
\frac{d Q^{*}}{d n}=\underbrace{\frac{\left(\theta^{*}\right)^{1-\beta}\left(1-\beta\left(1+\theta^{*}\right)\right) Z^{*}}{\theta^{*}\left(1+\theta^{*}\right)^{2}} \frac{\partial \theta^{*}}{\partial n}}_{+}+\underbrace{\frac{\left(\theta^{*}\right)^{1-\beta}}{1+\theta^{*}} \frac{\partial Z}{\partial K} \frac{\partial K^{*}}{\partial n} \lesseqgtr 0,}_{-}
$$

where the sign of the expression $\left(1-\beta\left(1+\theta^{*}\right)\right)=\frac{(1-\beta)\left((n-1) \alpha+R^{*} \beta\right)}{\alpha(1-\beta)(n-1)+R^{*} \beta n}>0$.

Again, the reaction consists of a static or short-run effect, which leads to an increase of output because of a more efficient input factor allocation. This increase of output is caused by the price change of the good produced in the oligopolistic sector, and a long-run effect, which is negative, is caused by the smaller capital stock. Thus, an increase of the degree of competition in the oligopolistic sector may lead to a decline of real income and consumer surplus in the long run. To illustrate this, we have calibrated Equation (45) along with the number of firms in the oligopolistic sector in Figure 4.

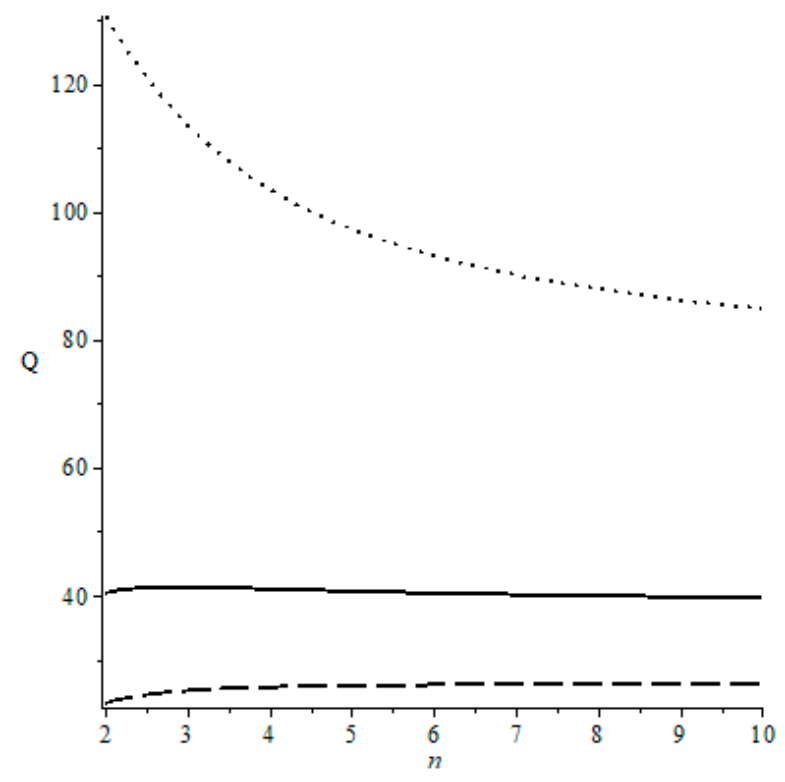

Figure 4. To calibrate Figure 4, we used log-linear utility function, a Cobb-Douglas production function, and the following parameter values: $q=0.8, A=20, \beta=0.09$, and $\alpha=0.55$ (dotted line); $\alpha=0.3$ (dashed line); and $\alpha=0.4$ (solid line).

Unlike the results of Laitner (1982), in our model, it is possible that the real income per period will decrease. Figure 4 presents three different scenarios based on production elasticity of capital. If the elasticity is sufficiently low, then the real income or the quantity of compound goods, $Q$, will increase with an increasing numbers of firms $(n)$ in the oligopolistic sector. If the elasticity is sufficiently high, the opposite happens-the steadystate quantity of $Q$ will decline with an increasing number of firms in the oligopolistic sector. It also can happen that the quantity of compounded goods will first increase with an increasing number of firms and then it will decrease. However, in our model, it is no longer clear if tougher competition will lead to an increased welfare in terms of real income or consumer surplus.

Proposition 5. If competition increases in the oligopolistic sector, it is in general ambiguous if an increase of the number of firms will lead to an increase or decline of real income or consumer surplus.

The reason for this outcome is that the increase of number of firms changes the intergenerational income distribution, and this change may lead to the fact that the income of 
the young generation declines sufficiently strongly that the reduction of income, followed by a reduction of savings, cannot be compensated by the increase of production caused the static efficiency gain.

Next, we consider how the aggregate consumption is affected by an increasing number of firms. We differentiate Equation (47) with respect to the numbers of firms in the oligopolistic sector. This gives the following:

$$
\frac{d C^{*}}{d n}=Z\left(\frac{\beta}{1-\beta}\right)[\underbrace{\left(\frac{1}{(n-1)^{2}}\right)\left(\frac{\theta^{*}}{1+\theta^{*}}\right)}_{+}+\underbrace{\left(\frac{n}{n-1}\right) \frac{1}{\left(1+\theta^{*}\right)^{2}} \frac{\partial \theta^{*}}{\partial n}}_{+}]+\underbrace{\left(\frac{n}{n-1}\right)\left(\frac{\beta}{1-\beta}\right)\left(\frac{\theta^{*}}{1+\theta^{*}}\right) \frac{\partial Z}{\partial K} \frac{\partial K^{*}}{\partial n}}_{-} \lesseqgtr 0 .
$$

The effect on the real consumption is similar to the aggregated quantity of compound goods. Again, the static component of short-run effect has a positive impact, while the dynamic effect on the capital accumulation has a negative impact on the aggregate consumption. We also illustrate this in Figure 5.

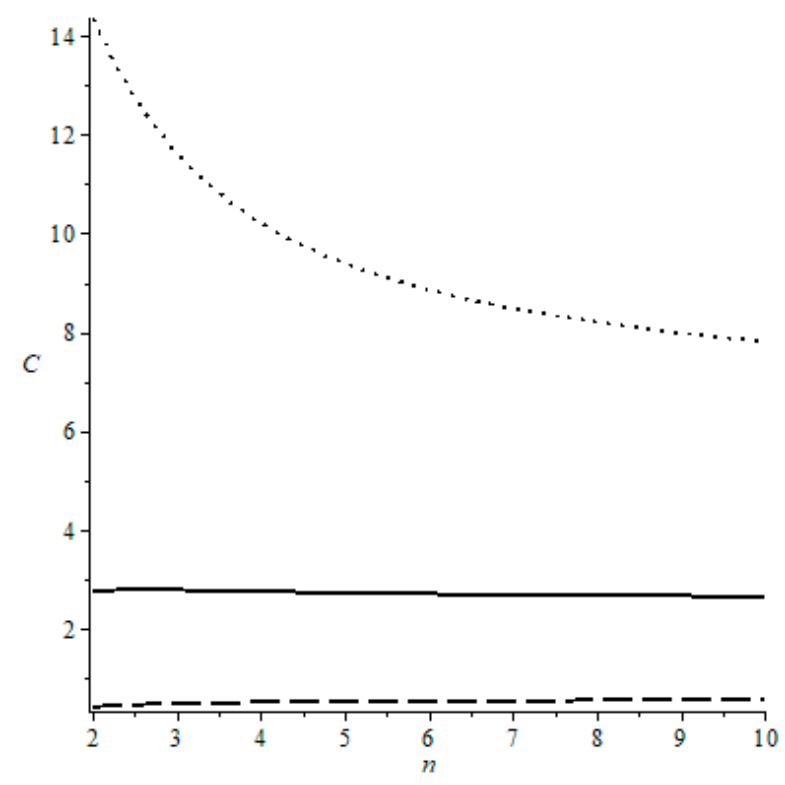

Figure 5. To calibrate the graphs, we used a log-linear utility function and a Cobb-Douglas production function with the following parameter values: $q=0.8, A=20, \beta=0.009$, and $\alpha=0.65$ (dotted line); $\alpha=0.3$ (dashed line); and $\alpha=0.53$ (solid line).

As shown above, regarding the real income, we have only varied the production elasticity of capital. If the elasticity is sufficiently low, the aggregate consumption will increase with an increasing number of firms in the oligopolistic sector; if the elasticity is sufficiently high, the aggregate consumption will decline; and if the elasticity is within certain range (neither too higher nor too low), the consumption has an inverted U-shape form. However, as noted above, these partly surprising results are an outcome of change of the inter-generational income distribution.

\subsection{Functional and Inter-Generational Income Distribution}

We begin with the nominal national income in terms of the product produced in the competitive sector. The nominal wage incomes are given by the following:

$$
W^{*}=(1-\alpha) Q^{C *}+p^{*}\left(1-\frac{1}{n}\right)(1-\alpha) Q^{O *}=(1-\alpha) Z^{*}=(1-\alpha) A\left(K^{*}\right)^{\alpha} .
$$


The aggregated nominal capital incomes, $R K^{*}$, are as follows:

$$
R K^{*}=\alpha Q^{C *}+p^{*}\left(1-\frac{1}{n}\right) \alpha Q^{O *}=\alpha Z^{*}=\alpha A\left(K^{*}\right)^{\alpha},
$$

and the nominal aggregated profits, $\Pi^{*}$, are given by the following:

$$
\Pi^{*}=\frac{p^{*} Q^{O *}}{n}=\left(\frac{1}{n-1}\right)\left(\frac{\theta^{*}}{1+\theta^{*}}\right) Z^{*}=\left(\frac{1}{n-1}\right)\left(\frac{\theta^{*}}{1+\theta^{*}}\right) A\left(K^{*}\right)^{\alpha}=\frac{\left(\theta^{*}\right)^{\beta}}{n-1} Q^{*} .
$$

If we aggregate these incomes, the nominal national income, $Y^{n}$, becomes the following:

$$
Y^{n}=\left(1+\left(\frac{1}{n-1}\right)\left(\frac{\theta^{*}}{1+\theta^{*}}\right)\right) A\left(K^{*}\right)^{\alpha}=Q^{C *}+p^{*} Q^{O *}
$$

The nominal national income is equal to the value of goods produced in both sectors, which are measured in terms of the good of the competitive market. The national income measured in terms of the compound good or in purchasing power is given by $Q^{*}$. We define the price level, $P^{*}$, in this economy as follows:

$$
P^{*}=\frac{Y^{n}}{Q^{*}}=\frac{n\left(1+\theta^{*}\right)-1}{(n-1)\left(\theta^{*}\right)^{\beta}} .
$$

Proposition 6. The steady-state price level $P^{*}$ depends negatively on the number of firms in the oligopolistic sector.

\section{Proof of Proposition 6.}

$$
\frac{d P^{*}}{d n}=-\frac{\theta^{*}}{(n-1)^{2}\left(\theta^{*}\right)^{1-\beta}}+\frac{n\left(\left(1+\theta^{*}\right) \beta-1\right)+1-\beta}{(n-1)\left(\theta^{*}\right)^{2-\beta}}<0,
$$

Because

$$
n\left(\left(1+\theta^{*}\right) \beta-1\right)+1-\beta=-\frac{(1-\beta)(n-1)(\beta+n-1) k^{*}}{(1-\beta)(n-1) k^{*}+\beta n A\left(k^{*}\right)^{\alpha}}<0 .
$$

The price level declines with the number of firms in the oligopolistic sector. Intuitively, this outcome is obvious, because the tougher the competition in the oligopolistic sector the lower is the price of the good produced in the oligopolistic sector and this reduces the price level.

Now we can calculate the income shares by dividing the labor incomes, the capital incomes and the profit incomes by $Y^{n}$. Then we get for the labor share $\left(L_{\text {share }}\right)$, the capital share $\left(K_{\text {share }}\right)$ and the profit share $\left(P_{\text {share }}\right)$ as follows:

$$
\begin{aligned}
& L_{\text {share }}=\frac{1-\alpha}{1+\left(\frac{1}{n-1}\right)\left(\frac{\theta^{*}}{1+\theta^{*}}\right)}, \\
& K_{\text {share }}=\frac{\alpha}{1+\left(\frac{1}{n-1}\right)\left(\frac{\theta^{*}}{1+\theta^{*}}\right)},
\end{aligned}
$$

and

$$
P_{\text {share }}=\frac{\left(\frac{1}{n-1}\right)\left(\frac{\theta^{*}}{1+\theta^{*}}\right)}{1+\left(\frac{1}{n-1}\right)\left(\frac{\theta^{*}}{1+\theta^{*}}\right)}
$$


As can be observed, the relationship between the income shares and the number of firms in the oligopolistic sector is determined by the term $\left(\frac{1}{n-1}\right)\left(\frac{\theta^{*}}{1+\theta^{*}}\right)$. In Appendix A, we show that $\frac{d\left[\left(\frac{1}{n-1}\right)\left(\frac{\theta^{*}}{1+\theta^{*}}\right)\right]}{d n}<0$.

Moreover, the following is clear:

$$
\begin{aligned}
& \frac{\partial L_{\text {share }}}{\partial n}>0, \\
& \frac{\partial K_{\text {share }}}{\partial n}>0 . \\
& \frac{\partial P_{\text {share }}}{\partial n}<0 .
\end{aligned}
$$

We can summarize these outcomes in the following proposition:

Proposition 7. An increase of the number of firms in the oligopolistic sector will lead to an increase of the labor income share and the capital income share and to a decline of the profit share.

Because of the fact that the income of the firm owners, who receive a wage income and a profit income, exceeds the income of the workers, who only receive a wage income, we can directly conclude that the income distribution of the working generation will become fairer, if the number of firms in the oligopolistic sector increases. Therefore, the incomes of the old generation will also be more equally distributed.

Accordingly, the real labor incomes, real capital incomes and real profit incomes are given by the following:

$$
\begin{gathered}
\frac{w^{*} L}{P^{*}}=\frac{1-\alpha}{1+\left(\frac{1}{n-1}\right)\left(\frac{\theta^{*}}{1+\theta^{*}}\right)} Q^{*}=\frac{1-\alpha}{P^{*}} Z^{*}, \\
\frac{R^{*} K^{*}}{P^{*}}=\frac{\alpha}{1+\left(\frac{1}{n-1}\right)\left(\frac{\theta^{*}}{1+\theta^{*}}\right)} Q^{*}=\frac{\alpha}{P^{*}} Z^{*}, \\
\frac{\Pi^{*}}{P^{*}}=\frac{\left(\frac{1}{n-1}\right)\left(\frac{\theta^{*}}{1+\theta^{*}}\right)}{1+\left(\frac{1}{n-1}\right)\left(\frac{\theta^{*}}{1+\theta^{*}}\right)} Q^{*}=\frac{\left(\frac{1}{n-1}\right)\left(\frac{\theta^{*}}{1+\theta^{*}}\right)}{P^{*}} Z^{*} .
\end{gathered}
$$

Finally, we can differentiate the real incomes with respect to the number of firms in the oligopolistic sector to investigate how the different income groups are affected by an increase of the number of firms (competition) in the oligopolistic sector.

$$
\begin{gathered}
\frac{d W^{*}}{d n}=\underbrace{-\frac{(1-\alpha)}{\left(P^{*}\right)^{2}} \frac{\partial P^{*}}{\partial n} Z^{*}}_{+}+\underbrace{\frac{(1-\alpha)}{P^{*}} \frac{\partial Z^{*}}{\partial k} \frac{\partial k^{*}}{\partial n}}_{-} \lesseqgtr 0, \\
\frac{d R^{*} K^{*}}{d n}=\underbrace{-\frac{\alpha}{\left(P^{*}\right)^{2}} \frac{\partial P^{*}}{\partial n} Z^{*}}_{+}+\underbrace{\frac{\alpha}{P^{*}} \frac{\partial Z^{*}}{\partial k} \frac{\partial k^{*}}{\partial n}}_{-} \lesseqgtr 0,
\end{gathered}
$$

An increase of the number of firms in the oligopolistic sector affects the incomes of capital owners, who represent the old generation and the incomes of the workers, who are members of the young generation in a similar way. The income shares will increase, and the reaction of the real income is ambiguous, because both the total production and price will decline. Hence, it is unclear if the real incomes of these two groups will rise or decline. To illustrate these outcomes, we have calibrated the outcomes (see Figures 6 and 7). 


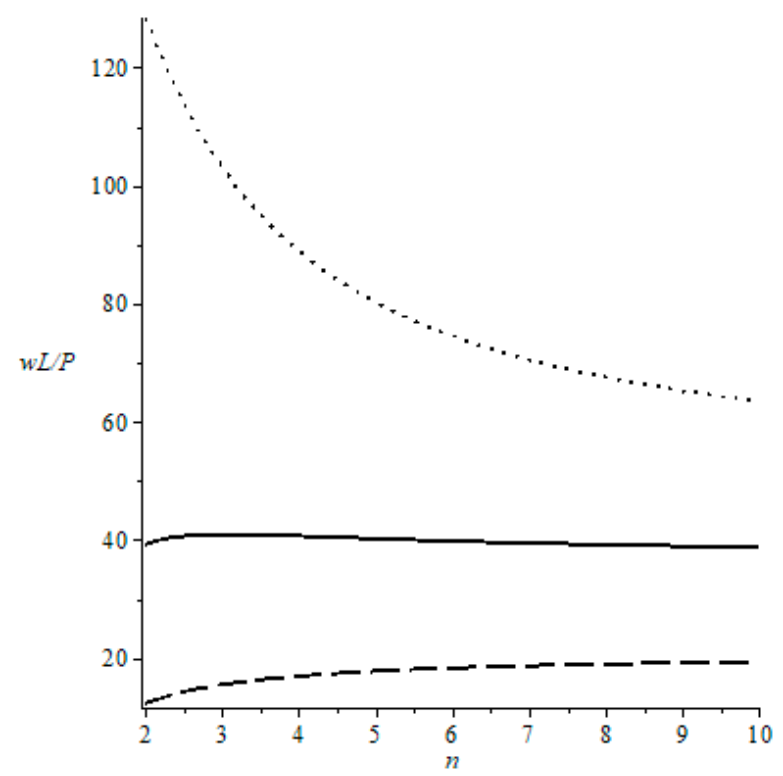

Figure 6. To calibrate the graphs, we used a log-linear utility function and a Cobb-Douglas production function with the following parameter values: $q=0.8, A=20, \beta=0.009$, and $\alpha=0.65$ (dotted line); $\alpha=0.3$ (dashed line); and $\alpha=0.53$ (solid line).

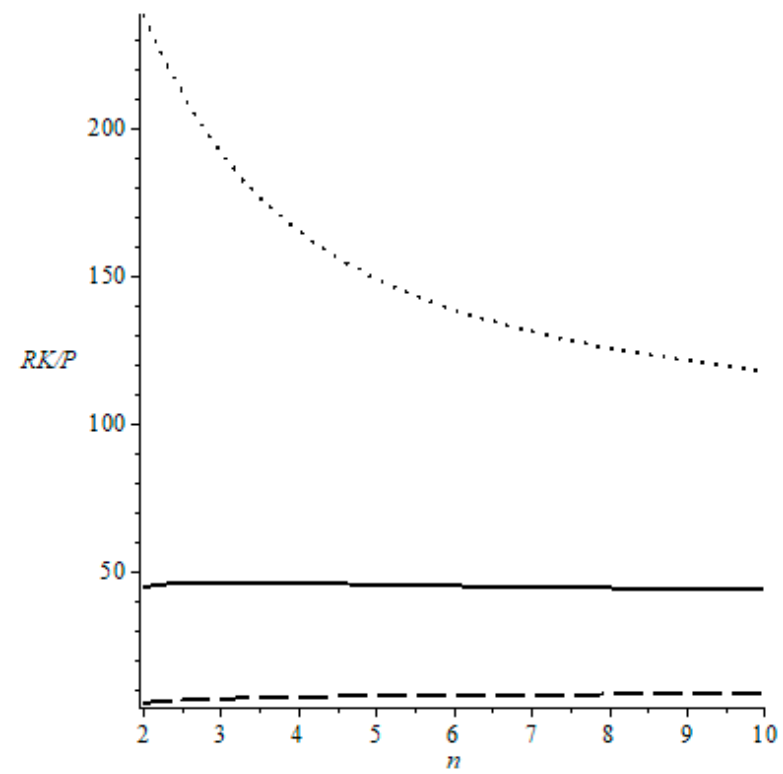

Figure 7. To calibrate the graphs, we used a log-linear utility function and a Cobb-Douglas production function with the following parameter values: $q=0.8, A=20, \beta=0.009$, and $\alpha=0.65$ (dotted line); $\alpha=0.3$ (dashed line); and $\alpha=0.53$ (solid line).

Proposition 8. If the number of firms in the oligopolistic sector increases, the reaction of the real capital and real labor incomes are ambiguous.

The reaction of the capital and labor incomes depend on two effects. On the one hand, the real income may decline because of the fact that the negative capital accumulation effect outperforms the positive effect generated by the improved production factor allocation, and on the other hand, the income share of workers and capital owners will increase, if the number of firms increases. If the negative capital accumulation effect is, in absolute terms, weaker than the efficiency effect, then the real incomes of workers and capital owners will increase with an increasing number of firms. 


\section{Conclusions}

In this paper, we modified the two-sector OLG model of Laitner (1982) and showed that his results may no longer hold if the members of the young generation, instead of the old generation, are the owners of the oligopolistic firms. In general, we argue that the reason for having contradictory outcomes is dependent on whether the oligopolistic profits are used for consumption or investment purposes. In our model, a significant share of the profits is saved, and the market power resulting from the oligopoly makes it possible to redistribute income from the old to the young generation; hence, part of this redistributed income is saved instead of consumed by the old generation. Consequently, a higher steadystate level of capital stock is realized, and this may lead to a higher level of real income and real consumption or consumer surplus. On the hand, the oligopolistic market structure will lead to the well-known distortions in the factor allocation. Moreover, whether the real income is higher with an oligopolistic market or with increasing competition depends on the size of the capital accumulation effect and the allocation effect. In contrast, in Laitner's model (1982), the intergenerational redistribution induced by the oligopoly works in the opposite direction, from the young to the old generation, because members of the old generation own the firms and receive the profits, where a share of the profits is generated from the income of the young generation. Additionally, in his model the capital accumulation is reduced because a part of the savings is used to buy the oligopolistic firms, where the firm value is determined by the discounted profits of the firm. Thus, more competition leads to a higher income of the young generation, to more capital accumulation because the value of firms declines, and thus to a higher steady state capital stock. In addition, the static distortions in the factor market will be reduced, and this will also increase the real income and surplus. Thus, it is imperative as to who owns the oligopolistic firms or, more generally, what happens with the profits. This outcome should have strong consequences for the anti-trust policy, because, in general, it may not be possible for an anti-trust administration to know what happens with monopoly profits. Therefore, as an extension to this study, it can be examined the extent to which the anti-trust policy measures lead to the desired outcomes, because, as noted from the analyses presented in this study, the opposite of what is desired may result.

With regard to oligopolistic multinational companies, it can be noted that, from a domestic policy view, the outflow of profits made by foreign-owned companies is as bad as if the profits are directly consumed. The second problem associated with oligopolies is that oligopolies induce a more unequal distribution of income. This holds for our model and Laitner's (1982) model, where we have shown that increasing number of firms makes the income distribution fairer, because the labor-income share increases, while the profit share declines. However, as we have shown above, the price of more equality can be a lower real income. Therefore, an extension to this study would be to investigate if a tax on profits associated with a redistribution of the tax revenue to the workers is more target aimed to reduce inequality than anti-trust policy. If this is the case, then according to our model, a redistributive tax policy should be applied and anti-trust policy should be given up because of the unpredictability of the outcomes of anti-trust policy.

Author Contributions: Writing — original draft preparation, P.J.S.; writing-review and editing, R.R.K. All authors have read and agreed to the published version of the manuscript.

Funding: P.J.S. thankfully acknowledges the financial support of the Changwon National University in 2021-2022 for this research.

Acknowledgments: We thank two anonymous reviewers and Frank Wernitz for their useful comments and suggestions. All remaining are ours.

Conflicts of Interest: The authors declare no conflict of interest. 


\section{Appendix A}

Proof. The term $\left(\frac{1}{n-1}\right)\left(\frac{\theta^{*}}{1+\theta^{*}}\right)$ can be written as follows:

$$
\left(\frac{1}{n-1}\right)\left(\frac{\theta^{*}}{1+\theta^{*}}\right)=\frac{(1-\beta)\left(\alpha A\left(k^{*}\right)^{\alpha-1}-1\right)}{(\beta+n-1) A\left(k^{*}\right)^{\alpha-1}}=\frac{(1-\beta)(1+\alpha q)}{n(1+q)-(1-\beta)} .
$$

If we differentiate this expression with respect to the number of firms, we get the following:

$$
\frac{d\left[\left(\frac{1}{n-1}\right)\left(\frac{\theta^{*}}{1+\theta^{*}}\right)\right]}{d n}=-\frac{(1-\beta)(1+\alpha q)(1+q)}{(n(1+q)-(1-\beta))^{2}}<0 .
$$

Additionally, it is obvious that the $\left(\frac{1}{n-1}\right)\left(\frac{\theta^{*}}{1+\theta^{*}}\right)$ will converge to zero if $n$ strives to infinity:

$$
\lim _{n \rightarrow \infty}\left(\frac{1}{n-1}\right)\left(\frac{\theta^{*}}{1+\theta^{*}}\right)=\lim _{n \rightarrow \infty} \frac{(1-\beta)(1+\alpha q)}{n(1+q)-(1-\beta)}=0 .
$$

\section{References}

Autor, David, David Dorn, Laurance F. Katz, Christina Patterson, and John Van Reenen. 2017. Concentrating on the Fall of the Labor Share. American Economic Review 107: 180-85. [CrossRef]

Autor, David, David Dorn, Laurance F. Katz, Christina Patterson, and John Van Reenen. 2020. The fall of the labor share and the rise of superstar firms. The Quarterly Journal of Economics 135: 645-709. [CrossRef]

Barkai, Simcha. 2020. Declining Labor and Capital Shares. The Journal of Finance 75: 2421-63. [CrossRef]

Barkai, Simcha, and Seth G. Benzell. 2018. 70 Years of US Corporate Profits. New Working Paper Series No. 22; Chicago: Stigler Center for the Study of the Economy and the State University of Chicago, Booth School of Business.

Belan, Pascal, Philippe Michel, and Bertrand Wigniolle. 2005. Does imperfect competition foster capital accumulation in a developing economy? Research in Economics 59: 189-208. [CrossRef]

Belan, Pascal, Philippe Michel, and Bertrand Wigniolle. 2007. Capital accumulation, welfare and the emergence of pension fund activism. FinanzArchiv/Public Finance Analysis 23: 54-82. [CrossRef]

Bergson, Abram. 1973. On monopoly welfare losses. American Economic Review 63: 853-70.

Busato, Francesco, and Bruno Chiarini. 2005. Heterogeneity in General Equilibrium: The Battle of Coalitions. In Economics: Complex Windows. Edited by Salzano Massimo and Alan Kirman. New Economic Windows. Milano: Springer, pp. 165-79. [CrossRef]

Chou, Chien-Fu, and Oz Shy. 1991. An overlapping generations model of self-propelled growth. Journal of Macroeconomics 13: 511-21. [CrossRef]

Diamond, Peter A. 1965. National debt in a neoclassical growth model. The American Economic Review 55: 1126-50.

Dixit, Avinash K., and Joseph E. Stiglitz. 1977. Monopolistic competition and optimal product diversity. American Economic Review 67: 297-308.

Dooley, Peter C. 1983. Consumer's Surplus: Marshall and His Critics. Canadian Journal of Economics/Revue Canadienne d'Economique 16: 26-38. [CrossRef]

Eaton, Jonathan. 1989. Monopoly Wealth and International Debt. International Economic Review 30: 33-48. [CrossRef]

Elsby, Michael W. L., Bart Hobijn, and Ayşegül Şahin. 2013. The decline of the US labor share. Brookings Papers on Economic Activity 2013: 1-63. [CrossRef]

Ethier, Wilfried J. 1982. National and international returns to scale in the modern theory of international trade. American Economic Review 67: 389-405.

Harberger, Arnold C. 1954. Monopoly and resource allocation. American Economic Review 44: 77-87.

Karabarbounis, Loukas, and Brent Neiman. 2014. The global decline of the labor share. Quarterly Journal of Economics 129: 61-103. [CrossRef]

Karabarbounis, Loukas, and Brent Neiman. 2018. Accounting for Factor-Less Income. NBER Working Paper 24404. Cambridge: NBER. [CrossRef]

Kumar, Ronald R., and Peter J. Stauvermann. 2020. Economic and Social Sustainability: The Influence of Oligopolies on Inequality and Growth. Sustainability 12: 9378. [CrossRef]

Kumar, Ronald R., and Peter J. Stauvermann. 2021. Does more market competition lead to higher income and utility in the long run? under review.

Laitner, John. 1982. Monopoly and Long-Run Capital Accumulation. Bell Journal of Economics 13: 143-57. [CrossRef] 
Mankiw, N. Gregory. 2020. Principles of Economics, 9th ed. Boston: Cengage.

Marshall, Alfred. 1890. Principles of Economics. London: MacMillan.

Mitchell, Shannon K. 1995. The political economy of quota rents in an international trade model. Economics and Politics 7: $243-61$. [CrossRef]

Parente, Stephen L., and Edward C. Prescott. 1999. Monopoly rights: A barrier to the riches. American Economic Review 89: 1216-33. [CrossRef]

Shy, Oz, and Rune Stenbacka. 2019a. An OLG model of common ownership: Effects on consumption and investments. Journal of Macroeconomics 62: 103155. [CrossRef]

Shy, Oz, and Rune Stenbacka. 2019b. Bank competition, real investments, and welfare. Journal of Economics 127: 73-90. [CrossRef]

Tse, Chung Yi. 2000. Monopoly, human capital accumulation and development. Journal of Development Economics 61: 137-74. [CrossRef] 